LBNL-53798

\title{
VENTILATION EFFICIENCIES AND THERMAL COMFORT RESULTS OF A DESK-EDGE-MOUNTED TASK VENTILATION SYSTEM
}

\author{
D Faulkner, WJ Fisk, DP Sullivan, and SM Lee \\ Indoor Environment Department \\ Environmental Energy Technologies Division \\ Lawrence Berkeley National Laboratory \\ Berkeley, CA, USA
}

September 2003

This work was supported by the Assistant Secretary for Energy Efficiency and Renewable Energy, Building Technologies Program of the U.S. Department of Energy (DOE) under Contract No. DE-AC03-76SF00098 


\title{
VENTILATION EFFICIENCIES AND THERMAL COMFORT RESULTS OF A DESK-EDGE-MOUNTED TASK VENTILATION SYSTEM
}

\author{
D Faulkner*, WJ Fisk, DP Sullivan, and SM Lee \\ Indoor Environment Dept., Lawrence Berkeley National Lab, Berkeley, CA, USA
}

\begin{abstract}
In chamber experiments, we investigated the ventilation effectiveness and thermal comfort of a task ventilation system with an air supply nozzle located underneath the front edge of a desk and directing air toward a heated mannequin or a human volunteer seated at the desk. The task ventilation system provided outside air, while another ventilation system provided additional space cooling but no outside air. Test variables included the vertical angle of air supply $\left(-15^{\circ}\right.$ to $45^{\circ}$ from horizontal), and the supply flow rate of ( 3.5 to $\left.6.5 \mathrm{~L} \mathrm{~s}^{-1}\right)$. Using the tracer gas step-up and step-down procedures, the measured air change effectiveness (i.e., exhaust air age divided by age of air in the breathing zone) in experiments with the mannequin ranged from 1.4 to 2.7 (median, 1.8), whereas with human subjects the air change effectiveness ranged from 1.3 to 2.3 (median, 1.6). The majority of the air change effectiveness values with the human subjects were less than values with the mannequin at comparable tests. Similarly, the tests run with supply air temperature equal to the room air temperature had lower air change effectiveness values than comparable tests with the supply air temperature lower $\left(\sim 5^{\circ} \mathrm{C}\right)$ than the room air temperature. The air change effectiveness values are higher than typically reported for commercially available task ventilation or displacement ventilation systems. Based on surveys completed by the subjects, operation of the task ventilation system did not cause thermal discomfort.
\end{abstract}

\section{INDEX TERMS}

Ventilation rates and strategies, Offices, Improved IAQ practices and technologies, Perceived air quality, thermal comfort

\section{INTRODUCTION}

Numerous studies have found that increased outside air ventilation rates in buildings are associated with reduced sick-building syndrome (SBS) health symptoms and with improvements in perceived air quality (Seppanen et al., 1999). Laboratory studies suggest that worker performance may improve with higher ventilation rates (Wargocki et al., 2000).

In general, increased ventilation rates will increase building energy use; therefore, technologies or practices that bring about the benefits of increased ventilation rates without energy penalties are highly desirable. One general approach for obtaining the benefits of increased ventilation rates without actually increasing the quantity of outside air supply or the associated energy use is to supply outside air in a manner that preferentially ventilates the breathing zone.

\footnotetext{
${ }^{*}$ Contact author email: D_Faulkner@lbl.gov
} 
To quantify the benefits of such air supply methods, we use the air change effectiveness (ACE). The ACE is a measurable parameter used to compare the effective ventilation rate at the breathing zone to the effective ventilation rate that would occur throughout the building with thoroughly mixed indoor air at the same rate of outside air supply. ASHRAE (1997), defines the ACE based on ages of air as follows

$$
A C E=\frac{\tau_{n}}{\tau_{\text {avg }}}
$$

where $\tau_{\mathrm{n}}$ is the nominal ventilation time constant and $\tau_{\text {avg }}$ is the average age of air at the breathing zone. The average age of air at a location is the average time elapsed since air at that location entered the building. $\tau_{\mathrm{n}}$ equals the average age of air exiting the building, which is identical to the indoor air volume divided by the rate of outside air supply. The practical interpretation is that $\mathrm{ACE}$ equals the effective ventilation rate at the location where people breathe divided by the ventilation rate that would occur throughout the ventilated space with perfect mixing. Thus, ACE values of 1.5 and 2.0 indicate $50 \%$ and $100 \%$ increases in effective ventilation rate at the breathing zone, relative to a perfectly mixed space with the same rate of outside air supply. Consequently, we seek ventilation technologies with ACEs that are as high as possible.

In the U.S., traditional ventilation systems supply a mixture of outside and recirculated air in high velocity jets so that the indoor air in rooms is often well mixed and the ACE is approximately unity (Fisk et al. 1992, 1997; Olesen and Seelen 1992; Persily 1986; Persily and Dols 1989). Task-ambient conditioning (TAC) systems are a ventilation technology with the potential for improved ACE. TAC systems may supply air from the floor, desk, or partitions and enable occupants to adjust the supply flow rate, direction, or temperature so that thermal conditions can be tailored to meet the individual's requirements. Most TAC systems supply a mixture of outside and recirculated air in relatively high velocity jets. The mixing caused by the air recirculation and the jet-induced air motions prevent ACE values from substantially exceeding unity. However, in experiments using these systems to supply only outside air, ACE values were sometimes significantly above unity, but generally still below 1.3 (Faulkner et al. 1993, 1993b, 1999; Fisk et al. 1991)

In prior experiments (Faulkner et al. 1999), one TAC system designed to supply only outside air had relatively high values of ACE. This system supplied air horizontally toward the seated worker's torso from the underside of the desk top, with nozzles located approximately $70 \mathrm{~cm}$ from the occupant, and resulted in ACE values up to 1.4. The system could also supply air vertically toward the face from the front edge of the desk, leading to ACE values up to 1.9, but these very high ACE values only occurred with the mouth and nose located precisely within the supply jet.

Our current research seeks to identify air supply methods that provides consistently high values of $\mathrm{ACE}$, for example by moving the outside air supply closer to the occupant and supplying air in low velocity jets. It is imperative that these air supply methods do not degrade thermal comfort, cause unacceptable drafts, or irritation at the face and eyes due to high air velocities. A similar research effort is underway at the Danish Technical University, with some promising results (Cermak and Majer 2000). We believe that this report chronicles the first research project to measure ACE values with human volunteers while using task ventilation. 


\section{METHODS}

The experimental system, illustrated in Figure 1, has a heated thermal mannequin or a human volunteer seated at a desk, with a personal air supply of $100 \%$ outside air located beneath the keyboard. The desk and mannequin or person are located within a nearly airtight experimental room with a volume of $27 \mathrm{~m}^{3}$, located within a thermally conditioned, nearly constant temperature, laboratory.

For reliable evaluations of the Task Ventilation system, the experimental room must have realistic sources of indoor air motion and mixing. In this facility, air motion is driven by the heated mannequin or person, the heat release and fan of a personal computer, heat release from a computer monitor and overhead light, and by a recirculating air stream. The air supply jet of the Task Ventilation system provides additional indoor air movement. The mannequin is wrapped in electrically resistant media located beneath clothing, and the voltage supplied to the media was adjusted to produce a total rate of sensible heat generation of $75 \mathrm{~W}$, typical of the sensible energy release of an adult office worker. The energy consumed by the personal computer, monitor, and overhead light are $50 \mathrm{~W}, 62 \mathrm{~W}$, and $29 \mathrm{~W}$, respectively. The recirculating air stream $\left(100 \%\right.$ recirculated air) has an air flow rate of $33 \mathrm{~L} \mathrm{~s}^{-1}$ equivalent to 4.4 indoor air volumes per hour or in terms of floor area $3.7 \mathrm{~L} \mathrm{~s}^{-1}$ per m$~_{2}$, and represents the airflow that would typically be used to heat or cool rooms. Air exited the experimental room from the recirculated airstream. The exhaust flow rate was adjusted manually, using a damper, to keep the room pressurized by $\sim 1.5 \mathrm{~Pa}$.

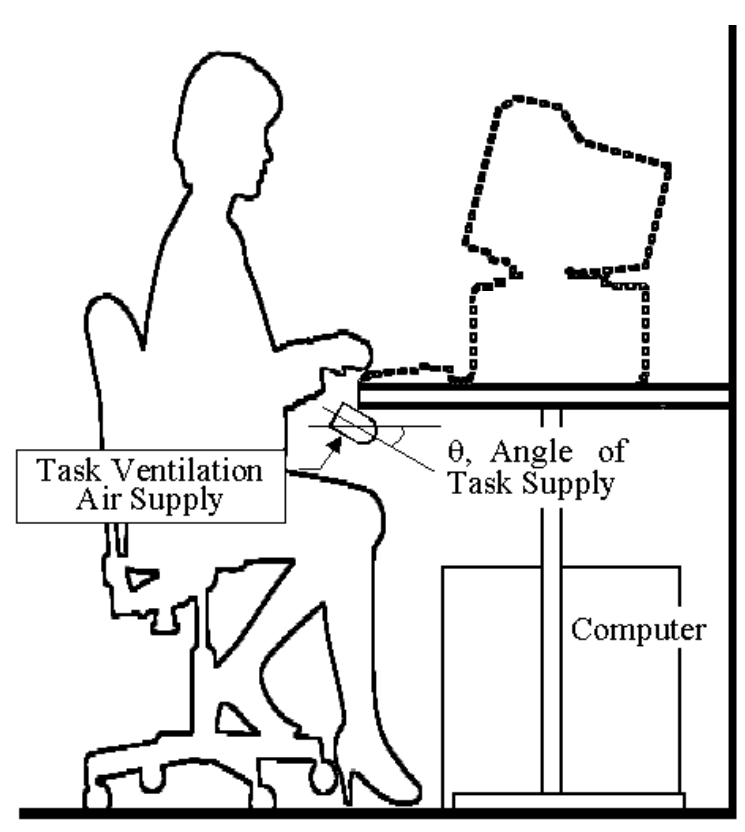

Figure 1. Side view of mannequin at desk in chamber and plan view of chamber with equipment identified.

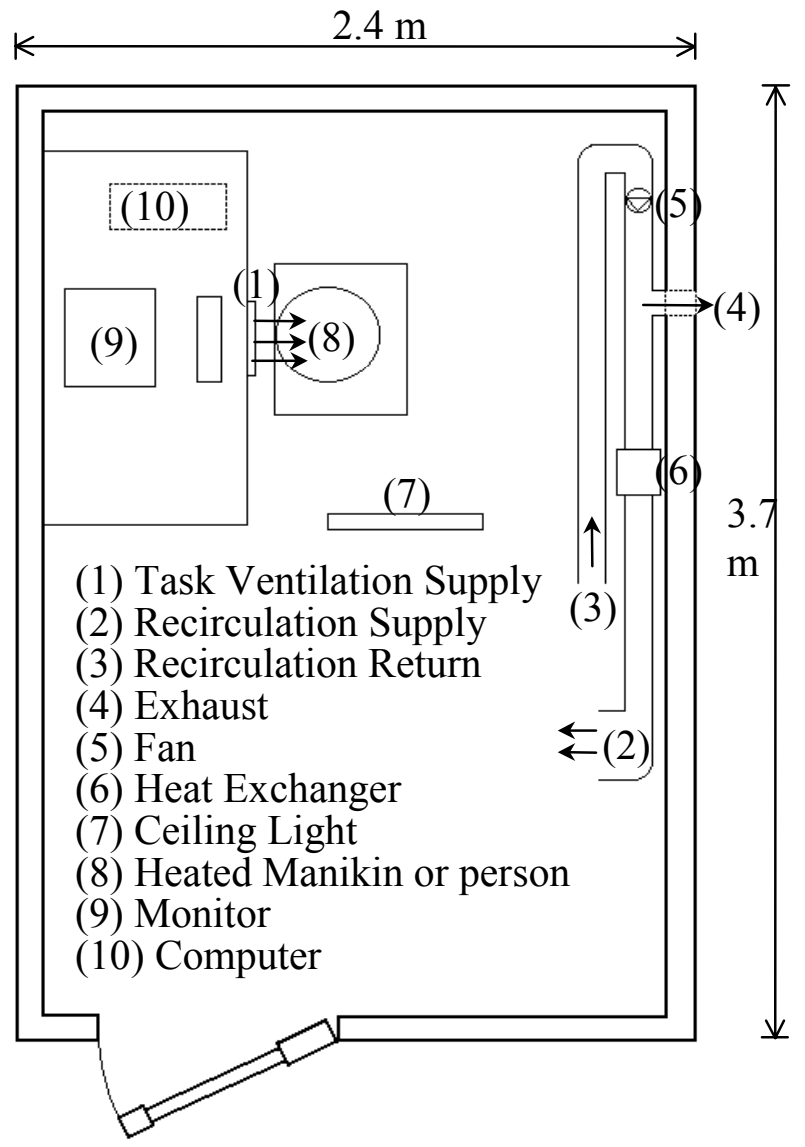


The air supply nozzle of the Task Ventilation system was located beneath the front edge of the desk, about $10 \mathrm{~cm}$ from the mannequin or person. It was constructed from a $3.8 \mathrm{~cm}$ diameter PVC pipe with a slot, $3.8 \mathrm{~cm}$ high and $30.5 \mathrm{~cm}$ long. The slot was filled with a 3.2 $\mathrm{mm}$ per side hexagonal flow straightener. The angle of the nozzle was adjustable so that air could be directed from $-15^{\circ}\left(15^{\circ}\right.$ downward from horizontal) to $+45^{\circ}$ (see Figure 1 ).

Our prior experiments (Faulkner et al. 1999) and those of Cermak and Majer (2000), plus airflow visualization studies, indicated that outside air supplied at a low velocity near the waist, will be entrained in the thermal plume flowing upward around the occupant and thus, be transported to the region of the mouth and nose. The exit area of the nozzle is $116 \mathrm{~cm}^{2}$, resulting in a nominal air supply velocity of $0.3 \mathrm{~m} \mathrm{~s}^{-1}$ with a supply flow rate of $3.5 \mathrm{~L} \mathrm{~s}^{-1}$. With such a low supply velocity, the air supply jet, when at room temperature, can just be sensed if one places their hand between the nozzle and the mannequin. Velocities measured about $8 \mathrm{~cm}$ in front of the upper chest were typically less than $0.1 \mathrm{~m} \mathrm{~s}^{-1}$. Because the theoretical work of Cermak and Majer (2000) suggests improved task ventilation system performance with reduced turbulence, the turbulence of the supply jet is reduced using a honeycomb flow straightener. Most tests (17 of 22) with the mannequin were performed at a supply temperature approximately $5-6{ }^{\circ} \mathrm{C}$ less than the ambient room temperature. This was possible by employing a small water-cooled heat exchanger located in the supply pipe for the Task Ventilation enabling the supply temperature to be reduced to as low as $17^{\circ} \mathrm{C}$. Five of the tests with the mannequin were conducted with the supply air temperature about equal to the average room air temperature.

Three tests were conducted with the supply air nozzles attached to the chair. The nozzles were rectangular with dimensions of $16 \mathrm{~cm} \times 8 \mathrm{~cm} \times 7 \mathrm{~cm}$, with the same flow straightener as the desk-mounted nozzle, and were attached to the side of the chair so that air was supplied toward the body at the waist level.

Human subjects were volunteers from the Indoor Environment Department at Lawrence Berkeley National Laboratory. Eleven volunteers participated in the study, 7 male and 4 female. Some subjects participated more than once. Most subjects used the computer to perform their normal work assignments. A few of the subjects spent part of their time reading at the desk, thus not using the computer. The study protocol was approved by the Committee for the Protection of Human Subjects at the University of California, Berkeley.

There were two types of tests in which the volunteers participated. In the first type, 6 of the subjects were given a thermal comfort survey (see Appendix A) every 15 minutes after either the supply nozzle angle $\left(15^{\circ}, 30^{\circ}, 45^{\circ}\right)$ and/or supply flow rate $(3.5,4.8,6.5 \mathrm{~L} / \mathrm{s})$ had been changed. The volunteers could observe the change made in nozzle angle, but not the flow rate. In a few cases, as a result of the answers to the survey and with the occupant's permission, the supply air temperature was changed from $1{ }^{\circ} \mathrm{C}$ warmer to $8{ }^{\circ} \mathrm{C}$ cooler than the room air temperature. All volunteers completed at least 6 surveys. Eight tests of a second type were tracer gas step-ups with some of the subjects completing the thermal comfort survey at the end of the step-up period. In a majority of both types of tests, the supply air temperature was slightly cooler $\left(-0.5 \pm 1.0{ }^{\circ} \mathrm{C}\right)$ than the central room air temperature.

The ACE was measured using well-established tracer gas stepup or decay procedures (ASHRAE 1997). During tracer stepups, sulfur hexafluoride $\left(\mathrm{SF}_{6}\right)$ tracer gas was continuously injected into the Task Supply duct at a location upstream of the supply fan to 
increase mixing of the tracer within the airstream. The injection rate was maintained at a constant value with a mass flow controller. Tracer gas injection continued for 3.5 to 9.5 hours, dependent upon the outside air flow rate. At the end of the stepups, $\mathrm{SF}_{6}$ concentration in the room's exhaust airstream was steady within the precision of our measurement system. For tracer gas decays, the tracer gas injection at the end of a stepup was stopped, allowing indoor $\mathrm{SF}_{6}$ concentrations to decay.

A quadrapole mass spectrometer with a multi-port valve was used to measure the tracer gas concentrations at 14 locations, every 2 minutes, around the mannequin and in the chamber. A subset of these locations was measured with the volunteers. To sample close to the mouth, the volunteers wore a headset, connected to the telephone, which had a sample tube attached that drew air from approximately $1 \mathrm{~cm}$ in front of the person's mouth. In this paper we concentrate on the measured concentrations at the mannequin's nose or the human's mouth and in the chamber exhaust stream. The mass spectrometer was calibrated before each experiment with 20 calibration gases, and has a very linear calibration curve.

\section{RESULTS}

The results of the ACE values at the breathing zone are provided in Figure 2. Measured values of ACE, range from 1.4 to 2.7 for the mannequin and 1.3 to 2.3 for the human volunteers. In tests with human volunteers, relative to comparable tests with the heated mannequin, the ACE values were substantially lower. In all but two tests with the supply temperature approximately equal to the room temperature or isothermal, the ACE values for both the mannequin and humans were lower, than comparable tests with cooler $\left(\sim 5-6{ }^{\circ} \mathrm{C}\right)$ supply temperatures. Also, three tests were done, with the supply nozzles attached to the chair and the values of ACE were 1.4 to 1.5 (results not shown in Figure 2).

To provide an indication of the repeatability of test results, duplicate tests were run at five configurations. In the set of five repeat tests, the ACE values at the nose differed, on average, by $0.3^{1}$. These differences could be due to both measurement errors and imperfect replication of test conditions. To provide a better indication of measurement uncertainty, we performed tests with fans vigorously mixing the indoor air, which should produce an ACE of 1.0. The measured $\mathrm{ACE}$ values at the nose were about 1.1, indicating that measurement errors were on the order of 0.1 .

When the nozzle angle was $20^{\circ}$ or larger, the majority of measured values of ACE in tests with the mannequin exceeded 1.8 and four measured values of ACE equaled or exceeded 2.0. However, with a nozzle angle of $0^{\circ}$, the ACE was smaller, ranging from 1.4 to 1.6. There was a very weak $\left(\mathrm{R}^{2}=0.18\right)$ association of $\mathrm{ACE}$ values with flow rate, with higher flow rates producing lower ACE values.

Most (90\%) of the subjects selected a thermal sensation between +1 and -1 on the ASHRAE thermal sensation scale (ASHRAE 2001). The \pm 1 rating translates to a predicted percent dissatisfied of $25 \%$. Also, in the survey, many (67\%) of the subjects reported that they wanted no change in air movement, indicating that the velocity of the air supply jet was not objectionable. Linear regressions of the ASHRAE thermal sensation for all subjects (using indicator variables) with: nozzle angle and supply air flow rate, produced non-significant coefficients for the nozzle angle and the supply flow rate. But the same analysis with the

\footnotetext{
${ }^{1}$ The largest difference in ACE values of duplicate tests was 0.7. But this large difference was atypical and not reproduced at locations 3 and $8 \mathrm{~cm}$ in front of the mouth.
} 
difference between the supply air temperature and the room air temperature as a variable, produced a significant $(\mathrm{p}=0.06)$ coefficient for the difference in the temperature. The negligible correlation between thermal sensation and attributes related to the task ventilation system such as nozzle angle and supply flow rate, indicates that these physical ventilation supply parameters have a minimal impact on reported thermal sensation.

\section{DISCUSSION}

With a positive air supply angle (20 to 45 degrees), the ACE was typically 1.7 or higher in tests with the mannequin, indicating a $70 \%$ or larger increase in effective ventilation rate at the breathing zone. In 5 of these tests, there was a $100 \%$ or larger increase in effective ventilation rate at the breathing zone. These values of ACE are much higher than typically measured in our prior studies of commercially available task ventilation systems and are also considerably higher than typically reported for displacement ventilation systems in rooms with a typical ceiling height.

There were 5 tests conducted with the mannequin in which the supply air temperature was at isothermal conditions. Four of the five tests resulted in lower ACE values than comparable tests with the supply air lower than the room temperature. We had expected the ACE values to be higher under isothermal conditions reasoning that the warmer supply air would not drop as the cooler air and thus more easily be caught in the thermal plume of the body. But there may be interactions between the thermal plume around the body and the jet from the supply nozzle that are not as we presumed. Perhaps the cooler supply air could become entrained in the thermal boundary layer of the body more easily than air at isothermal conditions.

The ACE values obtained in tests with real human volunteers were typically diminished, relative to the ACEs from comparable tests with the mannequin. But the tests with humans were isothermal, whereas the tests with the mannequin were not. Thus, based on the discussion above, the lower ACE values for the humans must be partially a result of the isothermal supply air temperature. We speculate that another cause for the reduced benefits of task ventilation with real human subjects was a consequence of people's movements that may have disrupted the flow of supply air from the task system in the thermal plume of the body. However, the values of ACE measured with human subjects were still often on the order of 1.5 , with one value of 2.3. Thus, the system increases the effective ventilation rate by about $50 \%$ or more relative to a typical overhead supply ventilation system. According to the ASHRAE Ventilation standard (ASHRAE 2001b) the minimum outdoor air supply rate can be decreased by one third (multiplied by 1/ACE), when the ACE equals 1.5. Thus, with this type of task ventilation system, the energy used for ventilation could be decreased by one third. Alternately, if the ventilation supply rate were not reduced, air quality at the breathing zone would normally be improved.

Figure 2 illustrates a couple of additional relationships that warrant comments. First, the ACE was higher with a nozzle angle of $20^{\circ}$ to $45^{\circ}$, relative to an angle of $0^{\circ}$. With a positive nozzle angle, the momentum of the fresh supply air must help the air reach the breathing zone. There most likely is an optimum nozzle angle, possibly $30^{\circ}$ to $45^{\circ}$ to deliver the maximum ACE. This optimum angle may be dependent upon the flow rate.

The second observation is that ACE values tended to be greater at lower flow rates. Also, lower flow rates will less likely cause a problem with drafts. Again, there must be an optimum flow rate, since allowing the flow rate to go to zero will not increase the ACE indefinitely. 
From the comfort data, it seems that the supply nozzle angle and flow rate are not important as far as thermal comfort, but based on the above discussion, may be important for air change effectiveness. Thus this system or one similar to it could be optimized for ACE without sacrificing thermal comfort.

There are several important questions still to be answered about this type of task ventilation air supply. The equipment and installation costs have not been estimated; however, special fans and ducting as well as the desk-mounted air supply nozzles would be required. This type of task ventilation air supply system may be easiest to implement in new buildings with underfloor air supply systems used for space conditioning, because the underfloor plenum is a convenient location for the outside air ductwork. We suspect that high rates of heat transfer through the small-diameter outside air ductwork will make it impractical to maintain a task ventilation supply air temperature substantially different from the temperature of air surrounding the ducts. In cold weather conditions, the incoming outside air would need to be filtered and heated sufficiently to prevent condensation on the exterior surfaces of the outside air ducts. During humid weather, the outside air would need to be filtered and dehumidified. With moderate outdoor temperatures and humidites, no heating or cooling of the outdoor air may be required.

Another question to be answered: which populations will receive the greatest benefits from the task ventilation systems? If a person spends very little time at their desk, then the increase in air change effectiveness will be unrealized. Thus, task ventilation may only be useful for people that spend a majority of their workday at their desk.

\section{CONCLUSIONS}

With the task ventilation air supply technology evaluated in this study, it should be possible to obtain an air change effectiveness of approximately 1.5 , which represents a $50 \%$ increase in effective ventilation rate at the breathing zone. Based on the current ASHRAE ventilation standard, with an ACE of 1.5 the outdoor air supply rate and associated energy use could be reduced by one third.

Our small thermal comfort survey indicates that the task ventilation air supply system, with low flow rates, will not create uncomfortable air movements and that operating conditions other than supply temperature will not substantially affect thermal comfort.

\section{ACKNOWLEDGEMENTS}

This work was supported by the Assistant Secretary for Energy Efficiency and Renewable Energy, Building Technology Program of the U.S. Department of Energy (DOE) under contract No. DE-AC03-76SF00098. We thank all of our subjects, for volunteering their time. Also, thanks to Michael Apte and Fred Bauman for their reviews. 


\section{REFERENCES}

ASHRAE. 1997. ANSI/ASHRAE 129-1997, Measuring air change effectiveness. American Society of Heating, Refrigerating, and Air Conditioning Engineers, Inc., Atlanta, GA.

ASHRAE. 1999. ANSI/ASHRAE Standard 62-1999, Ventilation for acceptable indoor air quality. American Society of Heating, Refrigerating, and Air Conditioning Engineers, Inc. Atlanta, GA.

ASHRAE. 2001. ASHRAE Handbook - Fundamentals, Chapter 8. American Society of Heating, Refrigerating, and Air Conditioning Engineers, Inc. Atlanta, GA.

ASHRAE 2001b ANSI/ASHRAE Standard 62-2001, Ventilation for acceptable indoor air quality. American Society of Heating, Refrigerating, and Air Conditioning Engineers, Inc., Atlanta, GA.

Cermak, R and Maj1er M. 2000. Development and evaluation of air terminal devices for personalized ventilation. ET-EP. 2000-09, Technical University of Denmark, Lyngby, Denmark.

Faulkner, D, Fisk, WJ, and Sullivan, DP. 1993. Indoor Air Flow and Pollutant Removal in a Room With Desk-Top Task Ventilation, ASHRAE Transactions 99(Pt. 2), pp. 750-758.

Faulkner, D, Fisk, WJ, and Sullivan, DP. 1993b. Indoor Airflow and Pollutant Removal in a Room With Floor-Based Task Ventilation: Results of Additional Experiments, Building and Environment 30(3), pp. 323-332.

Faulkner, D, Fisk, WJ, Sullivan, DP, and Wyon, DP. 1999. Ventilation Efficiencies of DeskMounted Task/Ambient Conditioning Systems, Indoor Air 9(4): 273-281.

Fisk, WJ and Faulkner, D. 1992. Air Exchange Effectiveness in Office Buildings: Measurement Techniques and Results, Proceedings of the 1992 International Symposium on Room Air Convection and Ventilation Effectiveness, July 22-24, Tokyo, pp. 213-223, published by ASHRAE, Atlanta, GA.

Fisk, WJ, Faulkner, D, Pih, D, McNeel, PJ, Bauman, FS, and Arens, EA. 1991. Indoor Air Flow and Pollutant Removal in a Room with Task Ventilation, Indoor Air 1(3): 247-262.

Fisk, WJ, Faulkner, D, Sullivan, DP, and Bauman, FS. 1997. Air Change Effectiveness and Pollutant Removal Efficiency During Adverse Mixing Conditions, Indoor Air 7(1): 55-63.

Olesen, BW and Seelen, J. 1992. Field measurements of air change effectiveness using tracer gas techniques, IAQ'92, Environments for People, pp. 301-308, Published by ASHRAE, Atlanta, GA.

Persily, AK. 1986. Ventilation effectiveness measurements in an office building, Proceedings of IAQ'86, Managing Indoor Air for Health and Energy Conservation, pp. 548-567. Published by ASHRAE, Atlanta, GA.

Persily, AK and Dols, WS. (1989) "Field measurements of ventilation and ventilation effectiveness in an office/library building", Indoor Air 1(3): 229-246.

Seppänen, OA, Fisk, WJ, and Mendell, MJ. 1999. Association of ventilation rates and $\mathrm{CO}_{2}$ concentrations with health and other human responses in commercial and institutional buildings. Indoor Air 9(4): 226-252.

Wargocki P, Wyon DP, Sundell J, Clausen G, and Fanger PO (2000) The effects of outdoor air supply rate in an office on perceived air quality, sick building syndrome (SBS) symptoms, and productivity. Indoor Air 10(4): 222-236. 


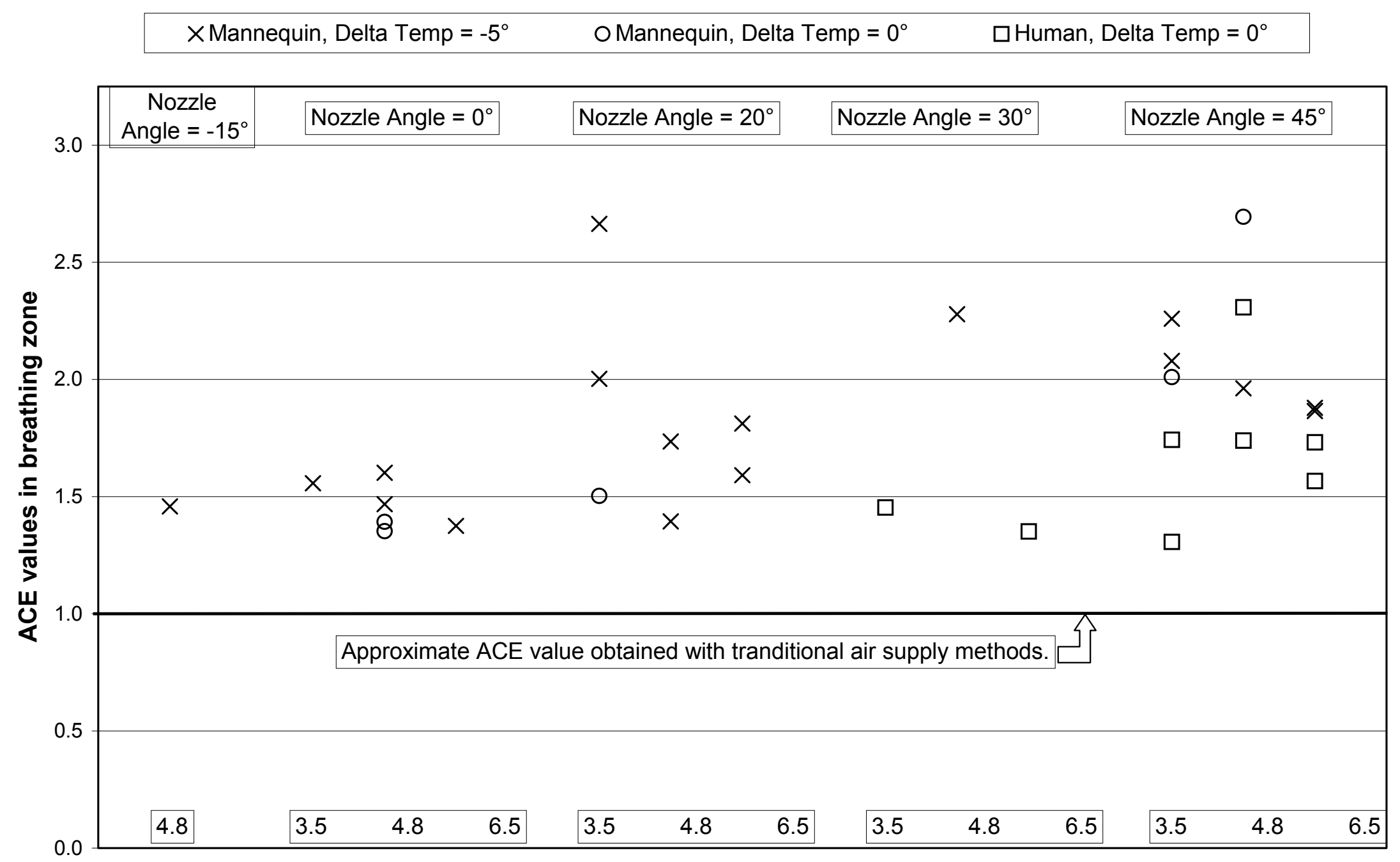

Flow rate, L/s

Figure 2. ACE values at outside air flow rates of $3.5,4.8$ and $6.5 \mathrm{~L} / \mathrm{s}$ and task supply nozzle angles from $-15^{\circ}$ to $45^{\circ}$. Supply air temperature was about $5^{\circ} \mathrm{C}$ lower than the room temperature or the same as the room temperature. 
Appendix A.

\section{COMFORT SURVEY}

1. Please check the box that best describes your present THERMAL PREFERENCE.
I want to be WARMER
I want NO CHANGE
I want to be COOLER

2. Place an $X$ on the scale below that best represents your OVERALL THERMAL SENSATION at the present time.

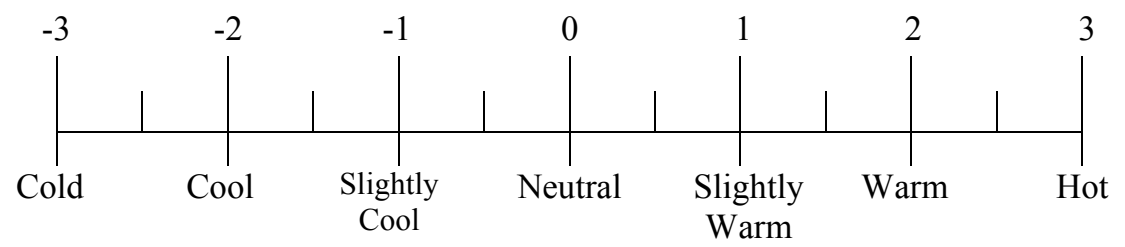

3. Do you feel COOL or WARM on any part of your body at the moment? If NO, please skip this question, if YES, mark the appropriate box.

\begin{tabular}{|l|l|l|l|}
\cline { 2 - 4 } \multicolumn{1}{c|}{ COOL } & WARM & COMFORTABLE \\
\hline HEAD & & & \\
\hline FOREHEAD & & & \\
\hline FACE & & & \\
\hline CHEST & & & \\
\hline ARMS & & & \\
\hline HANDS & & & \\
\hline STOMACH & & & \\
\hline LEGS & & & \\
\hline FEET & & & \\
\hline TOES & & & \\
\hline
\end{tabular}

4. Please check the box that best describes your present AIR MOVEMENT PREFERENCE.
I want LESS AIR MOVEMENT
where?
I want NO CHANGE
I want MORE AIR MOVEMENT $\rightarrow$ where?

5. Is the present rate of air movement ACCEPTABLE for carrying out paperwork at this desk?
YES
NO 
6. What is your sex?

$\square$ MALE

FEMALE

7. What is your age?
$\square 18-25$
$\square 26-35$
$\square 36-45$
$\square 46-55$
$\square 56-65$
$\square$ Over 65 